\title{
Expression of FKBP52 in the ovaries of PCOS rats
}

\author{
SHIYAN SONG ${ }^{1}$ and YONG TAN ${ }^{2}$ \\ ${ }^{1}$ Nanjing University of Chinese Medicine; ${ }^{2}$ Affiliated Hospital of Nanjing University of Chinese Medicine, \\ Nanjing, Jiangsu 210029, P.R. China
}

Received August 16, 2018; Accepted November 19, 2018

DOI: 10.3892/ijmm.2018.3998

\begin{abstract}
The present study aimed to examine the expression of FK-506 binding protein 52 (FKBP52) in the ovary tissues of rats with polycystic ovarian syndrome (PCOS) and its action on mediating androgen receptor (AR) through the mitogen-activated protein kinase (MAPK)/extracellular signal-regulated kinase (ERK) pathway. PCOS model rats were established by dehydroepiandrosteroneinjection.Enzyme-linked immunosorbent assay (ELISA) measured serum sex hormones. Hematoxylin and eosin (H\&E) staining was used to examine histological changes of the ovarian tissues. The expression levels of FKBP52 were detected by immunohistochemical (IHC) staining, reverse transcription-quantitative polymerase chain reaction (RT-qPCR) analysis and western blotting (WB). In addition, RT-qPCR analysis was used to detect the mRNA expression of $\mathrm{AR}$, and $\mathrm{WB}$ was used to detect the protein expression levels of AR, ERK1/2 and phosphorylated (p-) ERK1/2. In granulosa cell (GC) experiments, primary GCs were extracted and cultured. FKBP4 is the FKBP52-encoding gene, therefore, adenovirus vectors Ad-Oe-FKBP4-EGFP and Ad-siRNA-FKBP4-EGFP were constructed to examine the association among the above factors using the RT-qPCR and WB methods. In the animal experiment, the vaginal smear, H\&E staining and ELISA results showed that the PCOS model was successfully established. The IHC staining revealed that the
\end{abstract}

Correspondence to: Dr Yong Tan, Affiliated Hospital of Nanjing University of Chinese Medicine, 155 Hanzhong Road, Nanjing, Jiangsu 210029, P.R. China

E-mail: 1046233092@qq.com

Abbreviations: FKBP52, FK-506 binding protein 52; PCOS, polycystic ovarian syndrome; AR, androgen receptor; DHEA, dehydroepiandrosterone; ELISA, enzyme-linked immunosorbent assay; H\&E, hematoxylin and eosin; IHC, immunohistochemistry; RT-qPCR, reverse transcription-quantitative polymerase chain reaction; WB, western blotting; GC, granulosa cell; SD, Sprague-Dawley; SPF, specific-pathogen-free; PBS, phosphatebuffered saline; MAPK, mitogen-activated protein kinase; ERK, extracellular signal-regulated kinase

Key words: polycystic ovarian syndrome, FK-506 binding protein 52, androgen receptor, mitogen-activated protein kinase/extracellular signal-regulated kinase pathway, adenovirus vectors expression of FKBP52 in the GCs of the PCOS model group was higher than the remaining groups $(\mathrm{P}<0.01)$. The mRNA and expression levels of FKBP52 and AR in the PCOS model rats were significantly increased, when compared with levels in the other rats $(\mathrm{P}<0.05)$. The expression level of $\mathrm{p}$-ERK1/2 was also higher $(\mathrm{P}<0.05)$. In the $\mathrm{GC}$ experiment, following overexpression of the FKBP4 gene, the mRNA and expression levels of FKBP52 and AR were increased $(\mathrm{P}<0.05)$. The expression level of $\mathrm{p}$-ERK1/2 was also increased $(\mathrm{P}<0.05)$. Following FKBP4 gene silencing, the mRNA and expression levels of FKBP52 and $A R$ were decreased $(\mathrm{P}<0.05)$. The expression level of ERK1/2 was also decreased $(\mathrm{P}<0.05)$. However, the expression level of $\mathrm{p}$-ERK1/2 was increased $(\mathrm{P}<0.05)$. In conclusion, the upregulation of co-chaperone FKBP52 may mediate the activation of AR through the MAPK/ERK pathway.

\section{Introduction}

Polycystic ovarian syndrome (PCOS), which has been renamed metabolic reproductive syndrome, is the most common but little-known reproductive endocrine dysfunction and metabolic disorder in women worldwide $(1,2)$. It is characterized by hyperandrogenism, ovarian polycystic changes and rarity in ovulation or anovulation, and is often accompanied with obesity and insulin resistance (3-5). Diabetes, cardiovascular disease and cancer are its long-term complications. The prevalence of PCOS in Chinese women aged between 12 and 44 years was reported to be $7.4 \%$, according to the recommended diagnostic criteria for PCOS by the Androgen Excess Society (2006), and there is currently a gradual upward trend (6).

FK-506 binding protein 52 (FKBP52) is a subfamily of the FK506 binding protein family, and is commonly used as immunosuppressant. In 1985, FKBP52 was first identified by Tai et al in the establishment of an antibody against the EC1 epitope of rabbit uterine progesterone receptor complex (7). It was named due to its relative molecular weight of $\sim 52 \mathrm{kDa}$, and to date, it has been investigated in various experimental studies (8). As one of the Hsp90 co-chaperones that modify steroid hormone receptor activity, including regulation of receptor maturation, hormone binding and nuclear translocation, FKBP52 is a positive regulator of androgen receptor (AR) (9). It has been reported to be overexpressed in prostate cancer cell lines, and FK506 has an inhibitory influence on androgen-stimulated cell growth (10). Prostate needle biopsies of human patients were also found to have elevated FKBP52 levels (11). Furthermore, a number of compounds that suppress 
the adjustment by FKBP52 on AR function interdicted androgen-dependent gene expression and cell proliferation in prostate cancer cells (12). Preceding studies have also reported that male $52 \mathrm{KO}$ mice manifested phenotypes in accordance with partial androgen insensitivity $(9,13)$.

There have been few reports on FKBP52 in PCOS. In a previous study, by comparing normal women of childbearing age with patients with PCOS using gene chip technology, it was revealed that FKBP52 protein-coding genes were different, and this may be closely associated with abnormal androgen PCOS and obesity phenotype (14). In conclusion, FKBP52 may be considered a therapeutic target in diseases that rely on AR signaling pathways, and may be a contributor to endocrine-related and metabolic diseases, including PCOS.

The mitogen-activated protein kinase (MAPK)/extracellular signal-regulated kinase (ERK) pathway is a classic MAPK signal transduction pathway. It is involved in cell growth, differentiation, environmental stress adaptation, the inflammatory response and other important cell physiology/pathology processes. Activated AR in the cytoplasm may interact with several signaling molecules, which in turn converge on the activation of MAPK/ERK $(15,16)$. Studies on $5 \alpha$-dihydrotestost erone-responsiveness in prostate cancer cells showed increased phosphorylation of ERK-1/2 within 5 min, in a dose-dependent manner, and this response was AR-dependent as no effect was observed in AR-negative PC-3 prostate cancer cells (17). PCOS with insulin resistance and PCOS without insulin resistance showed statistically significant increases than control group $(\mathrm{P}<0.05)$ in expression of ERK1/2 in human luteinized granulosa cells (GCs); there was no significant difference between the PCOS groups (18).

The present study aimed to investigate the expression of FKBP52 in the ovarian tissues of PCOS rats. It is well-known that FKBP4 is the FKBP52-encoding gene. The adenovirus vectors Ad-Oe-FKBP4-EGFP and Ad-siRNA-FKBP4-EGFP were constructed to assess how FKBP52 mediates AR through the MAPK/ERK pathway following GC transfection.

\section{Materials and methods}

\section{Animal experiments}

Experimental animals. A total of 60 female Sprague-Dawley(SD) rats were provided by Shanghai Jie Esprit Experimental Animal Co., Ltd. [Shanghai, China; certificate no. SCXK (Shanghai) 2013-0006]. The animals were of specific-pathogen-free (SPF) grade and were 21 days old, with a mean body weight of $58 \pm 4 \mathrm{~g}$.

Replication of a PCOS animal model. The 60 21-day-old female SD rats of SPF grade were randomly divided into three groups following common feeding for 2 days; In the PCOS model (PM) group $(n=20)$, the rats were administered with dehydroepiandrosterone (DHEA; Sigma-Aldrich; Merck $\mathrm{KGaA}$, Darmstadt, Germany) at $6 \mathrm{mg} /(100 \mathrm{~g}$. d) $+0.2 \mathrm{ml}$ of injectable soybean oil via hypodermic injection for 35 consecutive days $(19,20)$; in the oil control (OC) group $(n=20)$, the rats were administered with $0.2 \mathrm{ml}$ of injectable soybean oil via hypodermic injection over the same period; in the normal control (NC) group $(n=20)$, the rats underwent no specific treatment. All animals were housed with a normal diet every day under a $12 \mathrm{~h}$ light/dark cycle at a temperature of $20-25^{\circ} \mathrm{C}$.
The model was successfully established when rats of the PM group showed loss of their estrous cycle. All rats were detected for body weight, ovarian weight, organ coefficient and vaginal smear, and serum was collected and analyzed via an enzyme-linked immunosorbent assay (ELISA). In addition, four ovaries of each group were randomly selected for histological examination of ovarian tissues to further evaluate the efficiency of the established model.

Specimen collection. Following the final day of modeling, all rats were weighed and then anesthetized with $2 \%$ sodium pentobarbital $(30 \mathrm{mg} / \mathrm{kg}$ ) for laparotomy to collect abdominal aorta blood and ovarian tissue specimens. When the 60 ovarian tissue specimens were weighed, the four ovarian specimens of each group were rapidly fixed in $4 \%$ paraformaldehyde fixative, embedded with paraffin, and cut into sections for hematoxylin and eosin (H\&E) staining and immunohistochemistry (IHC). The rest were stored in a refrigerator at $-80^{\circ} \mathrm{C}$, for reverse transcription-quantitative polymerase chain reaction (RT-qPCR) analysis and western blotting (WB). Serum was collected following centrifugation of all blood samples at $1000 \mathrm{x} \mathrm{g}$ for $10 \mathrm{~min}$.

$H \& E$ and IHC staining. Following $4 \mathrm{~h}$ of fixation in $4 \%$ paraformaldehyde fixative, the rat ovarian tissue specimens were subjected to conventional dehydration followed by paraffin-embedding and thin sectioning (4- $\mu$ m thick). H\&E staining was performed to examine the pathological structures of the rat ovary. IHC staining was conducted to detect the expression of FKBP52 in rat ovaries with an optical microscope (Leica DM2500, Leica Microsystems GmbH, Wetzlar, Germany).

ELISA. All serum samples were manipulated according to the manufacturer's protocol of every ELISA kit (Elabscience, Wuhan, China) for follicle stimulating hormone (FSH), luteinizing hormone $(\mathrm{LH})$, estradiol $\left(\mathrm{E}_{2}\right)$, progesterone $(\mathrm{P})$ and total testosterone (T). Experiments were performed in triplicate and repeated three times.

Fluorescence RT-qPCR analysis. A total of eight ovarian tissue specimens from each group were milled separately with TRIzol reagent (Beyotime Institute of Biotechnology, Haimen, China) using an IKA T 10 basic ULTRA-TURRAX disperser. A NanoDrop 2000 spectrophotometer was used to measure RNA concentration following extraction of total RNA from every specimen. Subsequently, the RNA was reverse-transcribed into cDNA using a reverse transcription kit (Takara Bio, Inc., Otsu, Japan). Eventually, $1.0 \mu \mathrm{l}$ cDNA was used as a template for PCR amplification ChamQ ${ }^{\mathrm{TM}} \mathrm{SYBR}^{\circledR}$ qPCR Master mix (High ROX Premixed) was purchased from Vazyme (Nanjing, China). The $10 \mu \mathrm{l}$ qPCR reaction mixture included the following: cDNA $1 \mu \mathrm{l}$, forward primer $(10 \mu \mathrm{M}) 0.5 \mu \mathrm{l}$, reverse primer $(10 \mu \mathrm{M}) 0.5 \mu \mathrm{l}, \mathrm{SYBR}$ qPCR mix $5 \mu \mathrm{l}, \mathrm{ddH}_{2} \mathrm{O} 3 \mu \mathrm{l}$. The primer sequences (Sangon Biotech Co., Ltd., Shanghai, China) used were as follows: GAPDH forward, 5'-GACATGCCG CCTGGAGAAAC-3' and reverse, 5'-AGCCCAGGATGCCCT TTAGT-3', FKBP52 upstream, 5'-CACTACACTGGCTGG CTGCT-3' and downstream, 5'-TGGTTGCCACAGCAATA TCC-3'; AR upstream, 5'-CCTTCACAGCAGCAGTCAGC-3' 
and downstream, 5'-CCTGATCTGGAGGAGCTGGT-3'. The amplification conditions were as follows: Pre-denaturation at $95^{\circ} \mathrm{C}$ for $10 \mathrm{~min}$, followed by 40 cycles of denaturation at $95^{\circ} \mathrm{C}$ for $15 \mathrm{sec}$ and annealing at $60^{\circ} \mathrm{C}$ for $1 \mathrm{~min}$. Data were collected and used for relative quantitative analysis with the $2^{-\Delta \Delta C q}$ method (21). The relative mRNA expression level was obtained by comparing data of the experimental group with those of the control group. The experiments were performed in triplicate and repeated three times.

WB. A total of eight ovarian tissue specimens from each group were milled separately with RIPA lysis buffer using IKA T 10 basic ULTRA-TURRAX. The detection of protein concentration was performed according to the manufacturer's protocol of the Enhanced BCA Protein Assay kit (Beyotime Institute of Biotechnology) following total protein extraction from every specimen. The electrophoretic separation of known antigenic proteins were run using the sodium dodecyl sulfate polyacrylamide gel electrophoresis method; $50 \mu \mathrm{g}$ protein were separated by $10 \%$ SDS-PAGE and then transferred onto a polyvinylidene fluoride membrane. Subsequently, the membranes were blocked in 5\% bovine serum albumin $(2 \mathrm{~h}$ at room temperature) and then incubated with primary $\left(4^{\circ} \mathrm{C}\right.$ overnight) and secondary antibodies ( $2 \mathrm{~h}$ at room temperature). Anti-FKBP52 antibody (EPR6618; cat. no. ab129097; 1:1,000), anti-androgen receptor antibody (EP670Y; cat. no. ab52615; 1:1,000) and anti-ERK1 + ERK2 antibody (EPR 17526; cat. no. ab184699; 1:10,000) were purchased from Abcam (Cambridge, UK). Phospho-p44/42 MAPK (Erk1/2) (Thr202/Tyr204) (D13.14.4E) XP ${ }^{\circledR}$ rabbit monoclonal antibody (cat. no. 4370; 1:2,000), GAPDH (14C10) rabbit monoclonal antibody (cat. no. 2118; 1:1,000) and anti-rabbit IgG and HRP-linked antibody (cat. no. 7074; 1:50,000) were purchased from Cell Signaling Technology, Inc. (Danvers, MA, USA). The blots were developed with Immobilon Western Chemiluminescent HRP Substrate (Merck KGaA). GAPDH served as an internal control. Quantitative analysis of protein expression was conducted by using ImageJ software 1.8.0 (National Institutes of Health, Bethesda, MD, USA).

\section{Cell experiments.}

Isolation and culture of GCs. A total of 10 female SD rats were provided by Shanghai Jie Esprit Experimental Animal Co., Ltd. [certificate no. SCXK (Shanghai) 2013-0006]. The animals were of SPF grade and were 21 days old, with a mean body weight of $58 \pm 4 \mathrm{~g}$. All animals were housed with a normal diet every day. Every rat was administrated with pregnant mare serum gonadotropin (20 IU; Sansheng Pharmaceutical Industry Co., Ltd., Ningbo, China) through intraperitoneal injection following 2 days of common feeding. After $48 \mathrm{~h}$, the animals were anesthetized with $2 \%$ sodium pentobarbital $(30 \mathrm{mg} / \mathrm{kg})$, sacrificed by cervical dislocation, and soaked in $75 \%$ alcohol for $30 \mathrm{~min}$. All ovaries, which were obtained by laparotomy, were placed into PBS and transferred into DMEM-F12 medium (Thermo Fisher Scientific, Inc., Waltham, MA, USA) following washing once again with PBS

The GCs were harvested by puncturing the follicles with microsurgical forceps, and $295 \%$ of the GCs were negatively stained using a Trypan blue assay. The GCs were then centrifuged at $300 \mathrm{xg}, 4^{\circ} \mathrm{C}$ for $5 \mathrm{~min}$, filtered with a cell sieve, and centrifuged again. The pellet was resuspended at $5 \times 10^{5} / \mathrm{ml}$ with DMEM-F12 medium for the RT-qPCR and WB methods, and at $5 \times 10^{4} / \mathrm{ml}$ for H\&E, immunocytochemistry (ICC), and immunofluorescence (IF) techniques in 6-well plates. The GCs were cultured in the incubator $\left(37^{\circ} \mathrm{C}, 5 \% \mathrm{CO}_{2}\right)$ and, after $72 \mathrm{~h}$, the cell adherence rate was $\sim 80 \%$.

Morphology and identification of GCs. H\&E staining was performed to observe the morphology of the GCs with an Olympus inverted microscope (Olympus Corporation, Tokyo, Japan). As FSH receptor (FSHR) is only expressed in GCs, ICC and IF were conducted to identify its purity. It met the requirements of subsequent trials when the positive rate was $>95 \%$.

Adenovirus vector transfection of GCs. The adenovirus vectors Ad-Oe-FKBP4-EGFP $\left(2 \times 10^{10} \mathrm{PFU} / \mathrm{ml}\right)$, Oe negative control virus $\left(10^{11} \mathrm{PFU} / \mathrm{ml}\right)$, Ad-siRNA-FKBP4-EGFP $\left(2 \times 10^{10} \mathrm{PFU} / \mathrm{ml}\right)$ and RNAi negative control virus $\left(5 \times 10^{10} \mathrm{PFU} / \mathrm{ml}\right)$, provided by Shanghai GeneChem Co., Ltd. (Shanghai, China) were constructed to transfect GCs. First, the multiplicity of infection (MOI) was ascertained by using different diluted concentrations of adenovirus vectors $(\mathrm{MOI}=$ virus titer $\mathrm{x}$ virus volume/cell numbers). The adenovirus vectors were diluted according to a concentration gradient between $10^{-2}$ and $10^{-7}$. When cell adherence rate reached $\sim 80 \%$ in 96 -well plates, the medium was discarded. The GCs were then cultured with medium containing different concentrations of virus vectors. After $12 \mathrm{~h}$, the normal medium was replaced. The expression of green fluorescence in the GCs was observed following $48 \mathrm{~h}$ of infection (Cell transfection rate $=$ number of green fluorescent cells/total number of cells $\times 100 \%$ ). When the rate reached $\sim 80 \%$, the virus concentration was considered the optimal dilution concentration.

Ad-Oe-FKBP4-EGFP transfection of GCs. The GCs were divided into three groups: Normal control group (CO group), EGFP-Oe group (EO group), and FKBP4-EGFP-Oe group (FO group). When the cell attachment rate reached $\sim 80 \%$, the medium was discarded. Based on previous pre-experiment results, DMEM-F12 medium was added to the $\mathrm{CO}$ group, DMEM-F12 medium with Oe negative control virus $(2 \mu \mathrm{l})$ was added to the EO group, and DMEM-F12 medium with FKBP4-Oe virus $(20 \mu \mathrm{l})$ was added to the FO group. After $12 \mathrm{~h}$, the medium was replaced with normal DMEM-F12 medium, and RNA and protein were obtained following $48 \mathrm{~h}$ of infection.

Ad-siRNA-FKBP4-EGFP transfection of GCs. The GCs were divided into three groups: Normal control group (CR group), EGFP-RNAi group (ER group), and FKBP4-EGFP-RNAi group (FR group). When the cell attachment rate reached $\sim 80 \%$, the medium was discarded. Based on previous pre-experiment results, DMEM-F12 medium was added to the CR group, DMEM-F12 medium with RNAi negative control virus (2 $\mu \mathrm{l})$ was added to the ER group, and DMEM-F12 medium with FKBP4-RNAi virus $(20 \mu \mathrm{l})$ was added to the FR group. After $12 \mathrm{~h}$, the medium was then replaced with normal DMEM-F12 medium, and RNA and protein were obtained following $48 \mathrm{~h}$ of infection. 
A

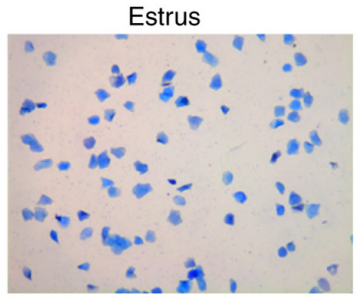

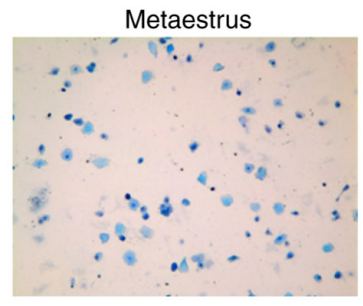

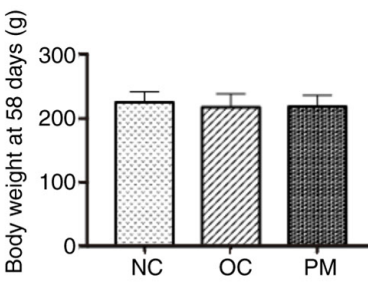

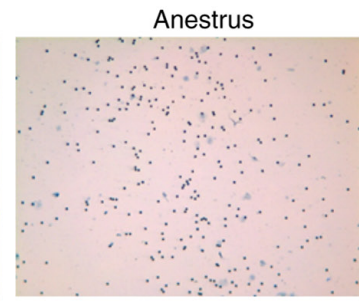
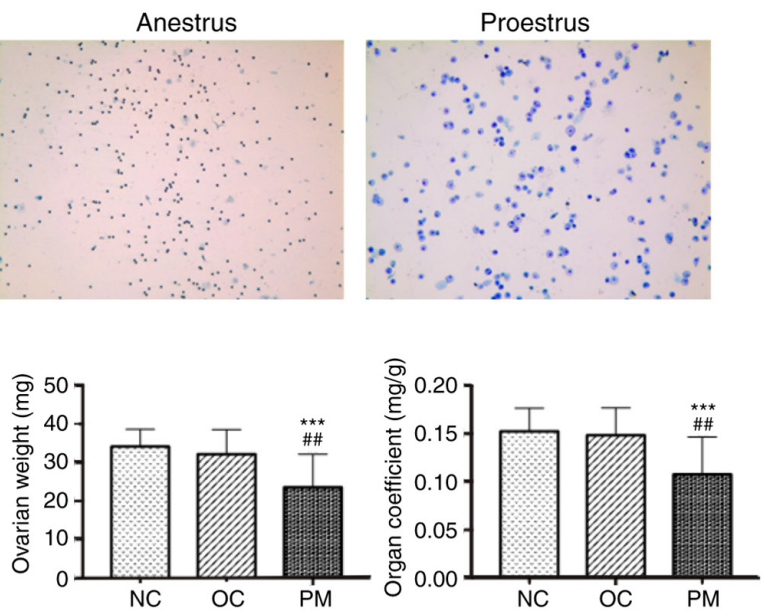

C
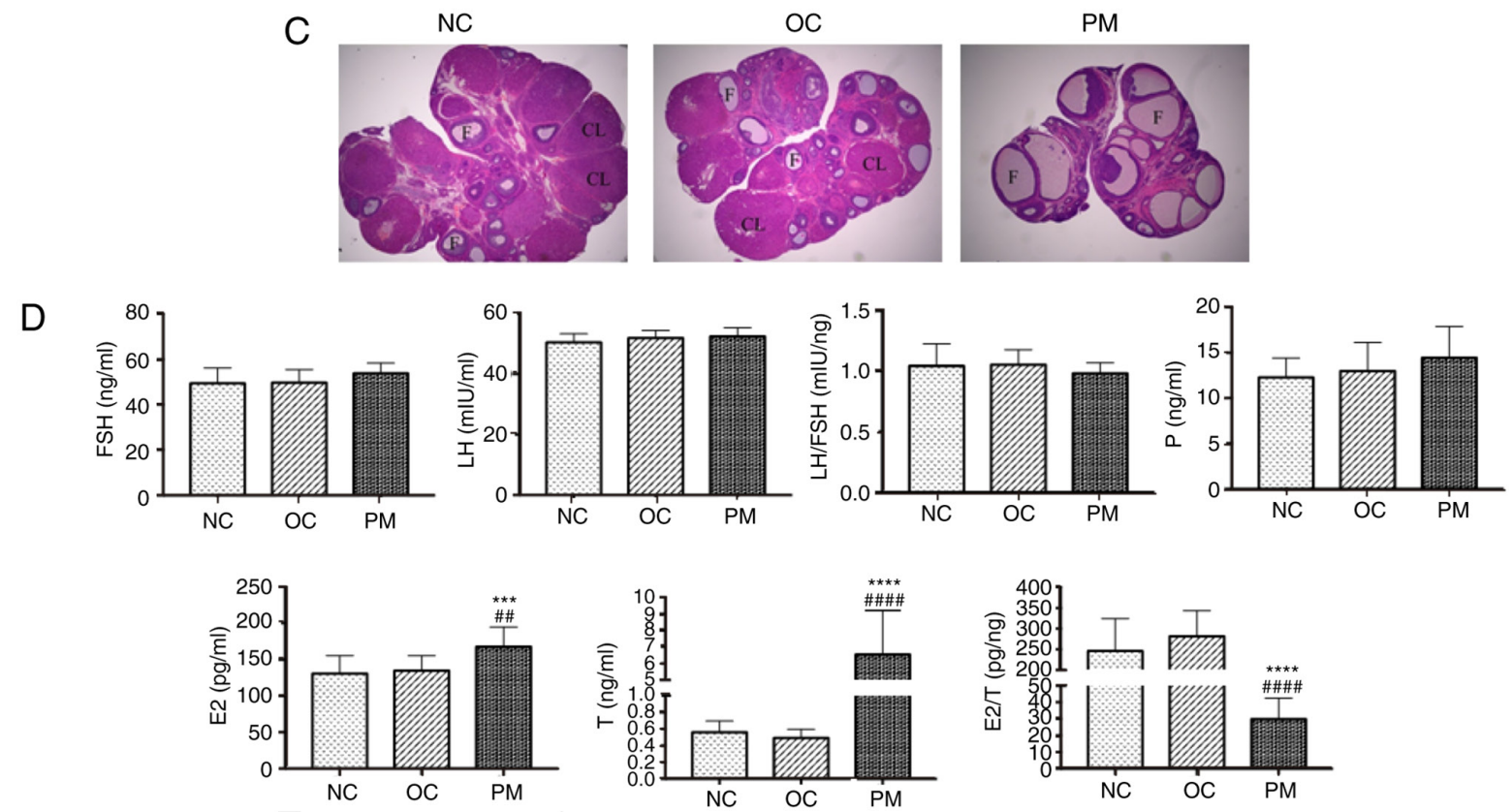

Figure 1. PCOS model evaluation. (A) Microscopy of stained smears of vaginal secretions (toluidine blue staining; magnification, $\mathrm{x} 100$; $\mathrm{n}=20$ per group). Estrus (keratinized epithelial cells); metaestrus (keratinized epithelial cells, epithelial cells, and white blood cells); anestrus (white blood cells); proestrus (epithelial cells). NC and OC groups had regular estrous cycle, however, rats in the PM group remained in the estrus period and lost their regular estrous cycles, suggesting anovulation. (B) Comparison of body weight, ovarian weight and organ coefficient among the three groups (mean \pm SD, $\mathrm{n}=20$ per group). Body weights at 21 and 58 days did not differ significantly among groups, whereas PM group ovarian weight and organ coefficient were significantly lower. (C) Comparison of rat ovarian structure (hematoxylin and eosin staining, $\mathrm{x} 25$ magnification, $\mathrm{n}=4$ per group). Morphological changes of rat ovarian tissue specimens were examined by light microscopy. In the NC and OC groups, microscopic examination revealed the presence of follicles of different developmental stages and a few corpora lutea; granulosa cells were orderly arranged with an intact form, mostly in 6-8 layers. In the PM group, the number of follicles with saccular dilatation increased, whereas follicles of different developmental stages and corpora lutea were rare; granulosa cells were arranged loosely in 2-3 layers, with atresia of some follicles. This result was consistent with PCOS characteristics. (D) Comparison of FSH, LH, LH/FSH, P, $\mathrm{E}_{2}$, T and $\mathrm{E}_{2} / \mathrm{T}$ among groups (mean $\pm \mathrm{SD}, \mathrm{n}=20$ per group). Sex hormones were measured by enzyme-linked immunosorbent assay. No significant differences in FSH, LH or $\mathrm{LH} / \mathrm{FSH}$ were found. However, $\mathrm{E}_{2}$ and $\mathrm{T}$ in the PM group were significantly higher, and $\mathrm{E}_{2} / \mathrm{T}$ was significantly lower. Experiments were performed in triplicate

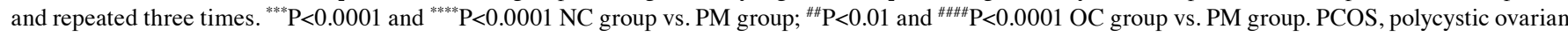
syndrome; PM, PCOS model; NC, normal control; OC, oil control; FSH, follicle stimulating hormone; LH, luteinizing hormone; $\mathrm{E}_{2}$, estradiol; P, progesterone; $\mathrm{T}$, total testosterone; F, follicle; CL, corpora lutea; SD, standard deviation.

Statistical analysis. The statistical analysis was performed using GraphPad Prism 7 software (GraphPad Software, Inc., La Jolla, CA, USA). The measurement data are expressed as the mean \pm standard deviation. A normality test and homogeneity of variance test were performed prior to making comparison between the groups. Comparisons of three samples were performed using one-way analysis of variance at the 0.05 level and multiple comparison between the groups was performed using Tukey method. Variables that did not meet a normal distribution were analyzed using a Kruskal-Wallis test.

\section{Results}

PCOS rats show loss of regular estrous cycle. At 35 days following DHEA treatment, the rats in the PM group had lost their regular estrous cycles and all of remained in the estrus period. Microscopy of stained smears of vaginal secretions 

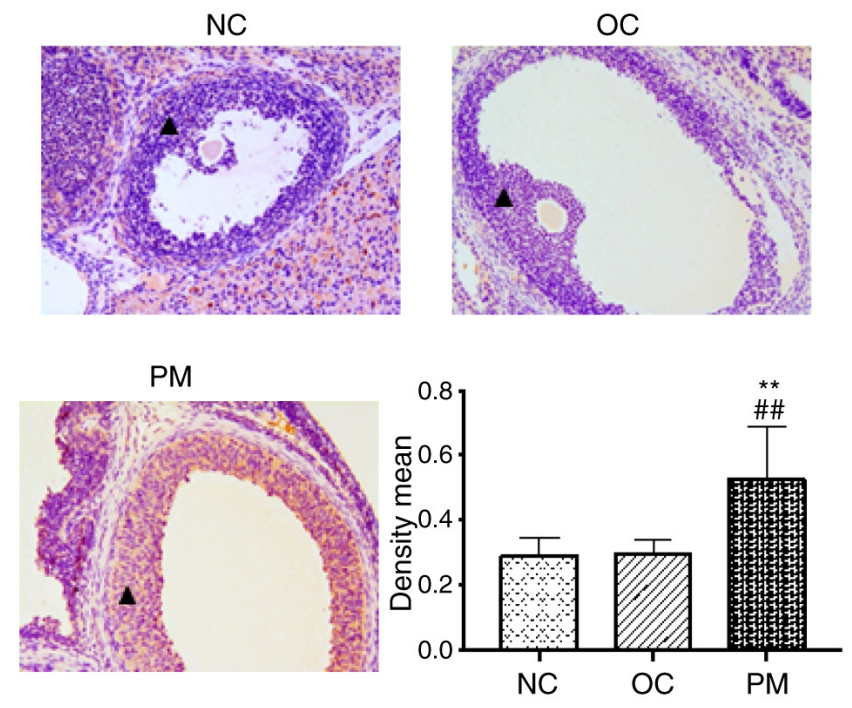

Figure 2. Comparison of the expression of FKBP52 in the ovaries of three groups (immunohistochemistry; magnification, $\mathrm{x} 200$; GCs, $\mathrm{n}=4$ per group). FKBP52-positive staining (yellow) was present in the nucleus and cytoplasm (indicated by black triangle) among all types of cells in the rat ovary. In GCs, expression of FKBP52 in the PM group was higher than in the other two groups. ${ }^{* *} \mathrm{P}<0.01 \mathrm{NC}$ group vs. $\mathrm{PM}$ group; ${ }^{\# \#} \mathrm{P}<0.01 \mathrm{OC}$ group vs. $\mathrm{PM}$ group. FKBP52, FK-506 binding protein 52; PM, polycystic ovarian syndrome model; NC, normal control; OC, oil control.

showed the presence of large numbers of keratinized cells, suggesting anovulation. By contrast, the rats in the NC and OC group had a regular estrous cycle (Fig. 1A).

Ovarian weight and organ coefficient are decreased in PCOS rats. The body weights of the rats at 21 and 58 days among the three groups showed no statistically significant difference. However, the ovarian weight and organ coefficient of the PM group were significantly lower than those in the other two groups (Fig. 1B).

Pathological structures of rat ovaries. Morphological changes in the rat ovarian tissue specimens were examined by light microscopy. In the NC and OC groups, microscopic examination revealed the presence of follicles of different developmental stages and a few corpora lutea; arrangement of the GCs was orderly with an intact form, mostly in 6-8 layers. In the PM group, the number of follicles with saccular dilatation increased whereas few follicles of different developmental stages and corpora lutea were observed; the GCs were arranged loosely in 2-3 layers, and with atresia of certain follicles. This result was consistent with PCOS characteristics (Fig. 1C).

PCOS rats have higher $E_{2}$ and $T$ levels and lower $E_{2} / T$ levels. There were no statistically significant differences in the levels of FSH, LH or LH/FSH in the rats among the three groups. However, the levels of $\mathrm{E}_{2}$ and $\mathrm{T}$ in the PM group were significantly higher than those in the other two groups, and $\mathrm{E}_{2} / \mathrm{T}$ was significantly lower. The experiments were performed in triplicate and repeated three times (Fig. 1D).

FKBP52 is increased in ovarian sections of PCOS rats. FKBP52-positive staining (yellow) was present not only in the nucleus, but also in the cytoplasm among all types of cell in the rat ovary. In the GCs, the expression of FKBP52 in the PM group was higher than in the other two groups (Fig. 2).

PCOS rats have higher $m R N A$ expression levels of FKBP52 and $A R$. The mRNA expression levels of FKBP52 and AR in the rat ovarian tissues of the PM group were significantly higher than those in the NC and OC groups. There was no statistically significant difference between the $\mathrm{NC}$ and OC groups. The experiments were performed in triplicate and repeated three times (Fig. 3A).

PCOS rats have higher protein expression levels of FKBP52, $A R$ and $p$-ERK1/2. The protein expression levels of FKBP52, $\mathrm{AR}$ and P-ERK1/2 in the rat ovarian tissues of the PM group were significantly higher than those of the NC and OC groups. There was no statistically significant difference between the $\mathrm{NC}$ and OC groups. The protein expression of ERK1/2 did not differ significantly among the three groups. The experiments were performed in triplicate and repeated three times (Fig. 3B).

Morphology and identification of GCs. The GCs exhibited a polygonal or cuboidal appearance under inverted phase contrast microscopy on adhering to the culture surface, proliferating, and spreading to form a monolayer (Fig. 4A). FSHR-positive staining (yellow) was present in the nucleus and the cytoplasm of the GCs (Fig. 4B). Therefore, IF staining was performed. The positive rate was $>95 \%$, therefore, the GCs extracted met the requirements of subsequent trials (Fig. 4C).

Expression of green fluorescence in GCs. Based on the preliminary trial, appropriate results were obtained following calculation according to the formula of MOI: For the Oe negative control virus, the optimal dilution concentration was $10^{-3}$, $\mathrm{MOI}=200$; the optimal dilution concentration of the FKBP4-Oe virus was $10^{-2}$, MOI=400; the optimal dilution concentration of RNAi negative control virus was $10^{-3}$, MOI=100; the optimal dilution concentration of FKBP4-RNAi virus was $10^{-2}$, $\mathrm{MOI}=400$. The cell transfection rate was $>80 \%$ (Fig. 5A-D).

mRNA expression levels of FKBP52 and AR increase following overexpression of FKBP4. The mRNA expression levels of FKBP52 and AR in the FO group were significantly higher than those in the $\mathrm{CO}$ group and EO group. There was no statistically significant difference between the $\mathrm{CO}$ group and EO group. The experiments were performed in triplicate and repeated three times (Fig. 6A).

Protein expression levels of FKBP52, AR and p-ERK following the overexpression of $F K B P 4$. The protein expression levels of FKBP52, AR and p-ERK1/2 in the FO group were significantly higher than those in the $\mathrm{CO}$ group and $\mathrm{EO}$ group. There was no statistically significant difference between the $\mathrm{CO}$ group and EO group. The protein expression of ERK1/2 did not differ significantly among the three groups. The experiment was repeated three times (Fig. 6B).

mRNA expression levels of FKBP52 and AR decrease following FKBP4 silencing. The mRNA expression levels of FKBP52 and AR in the FR group were significantly lower than those in the CR group and ER group. There was no statistically 

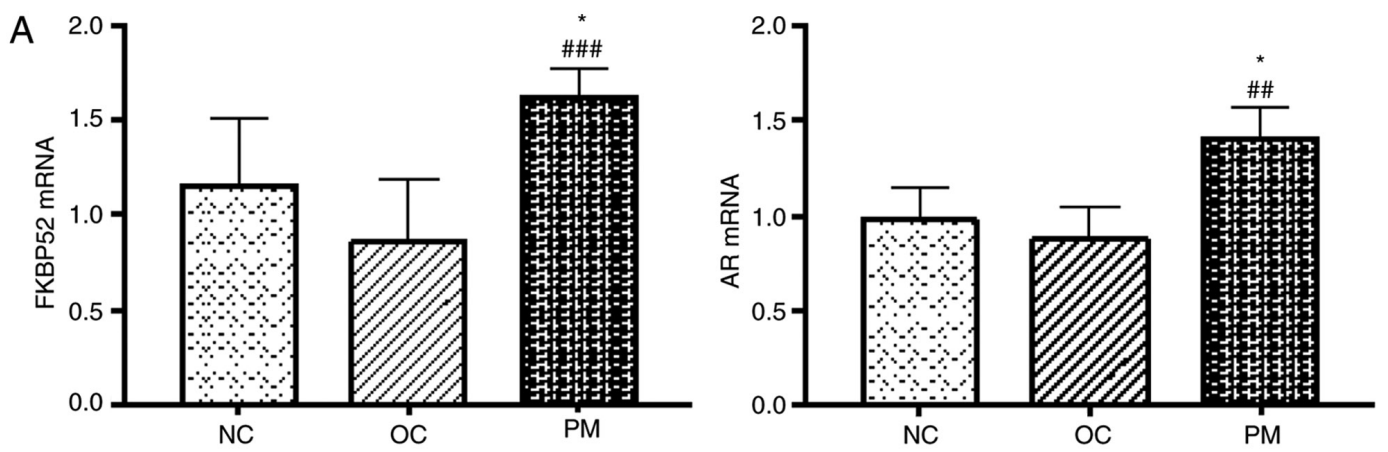

B
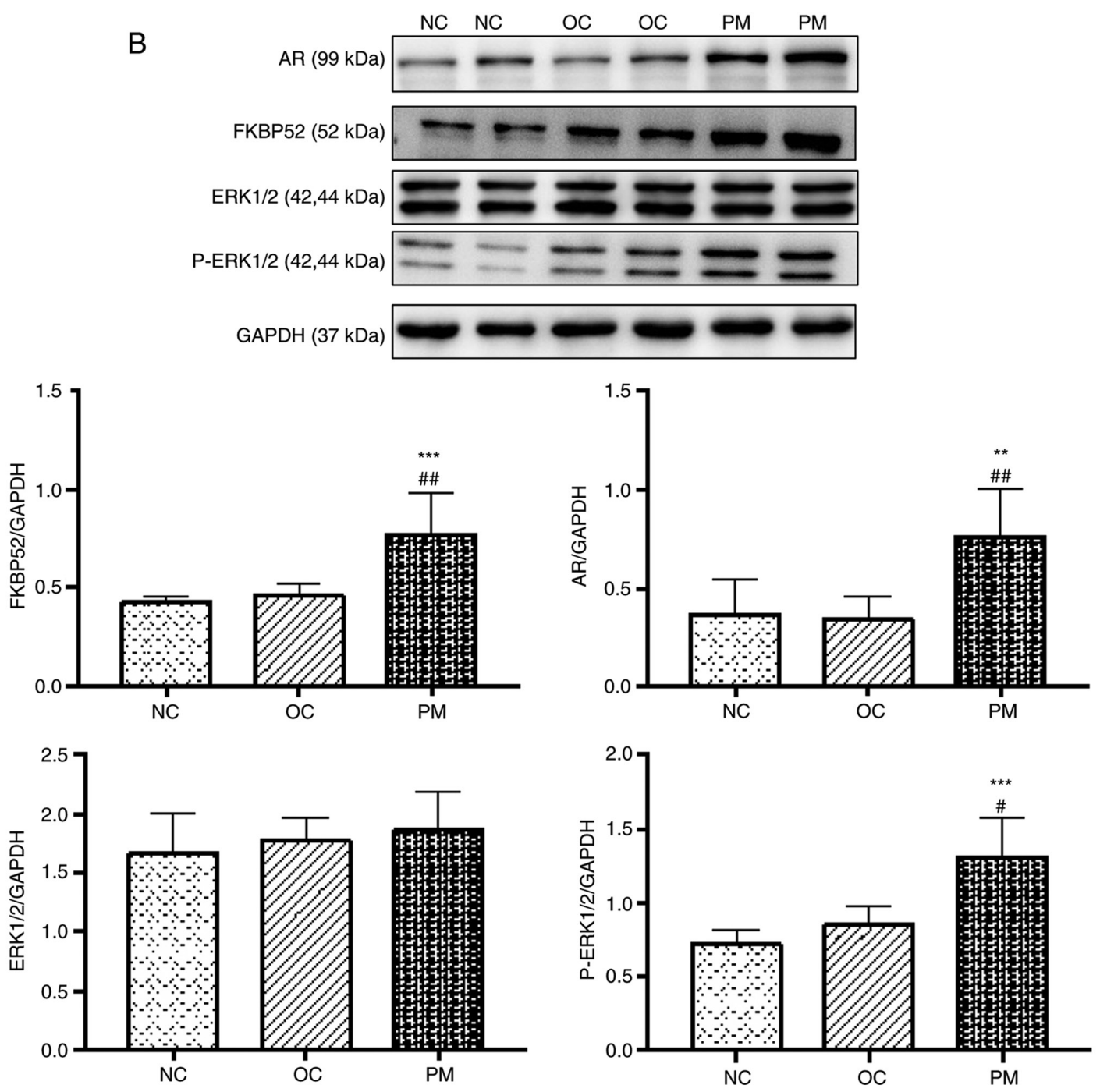

Figure 3. Expression of FKBP52, AR, ERK1/2 and p-ERK1/2 in rats. (A) Comparison of mRNA expression levels of FKBP52 and AR among the three groups (mean \pm SD, $n=8$ per group). The mRNA expression levels of FKBP52 and AR in the rat ovarian tissues of the PM group were significantly higher than those in the $\mathrm{NC}$ and OC groups. No significant difference was found between the NC and OC groups (P>0.05). (B) Comparison of protein expression levels of FKBP52, AR, ERK1/2 and p-ERK1/2 among the three groups (mean $\pm \mathrm{SD}, \mathrm{n}=8$ per group). The protein expression levels of FKBP52, AR and p-ERK1/2 in the rat ovarian tissues of the PM group were significantly higher than those in the NC and OC groups. No significant difference was found between the NC and OC groups. Protein expression of ERK1/2 did not differ significantly among the groups. Experiments were performed in triplicate and repeated three times. ${ }^{*} \mathrm{P}<0.05$, ${ }^{* *} \mathrm{P}<0.01$ and ${ }^{* * * *} \mathrm{P}<0.001 \mathrm{NC}$ group vs. PM group; ${ }^{\#} \mathrm{P}<0.05,{ }^{\# \#} \mathrm{P}<0.01$ and ${ }^{\# \# \#} \mathrm{P}<0.001 \mathrm{OC}$ group vs. PM group. FKBP52, FK-506 binding protein 52; AR, androgen receptor; ERK1/2, extracellular signal-regulated kinase; p-ERK1/2, phosphorylated ERK1/2; PM, polycystic ovarian syndrome model; NC, normal control; OC, oil control; SD, standard deviation.

significant difference between the CR group and ER group. The experiments were performed in triplicate and repeated three times (Fig. 6C).

Protein expression levels of FKBP52, AR and ERK decrease, and that of p-ERK increases following FKBP4 silencing. The protein expression levels of FKBP52, AR and ERK1/2 in the FR group were significantly lower than those in the CR group and ER group, whereas p-ERK showed the opposite result. There was no statistically significant difference between the CR group and ER group. The experiment was repeated three times (Fig. 6D). 

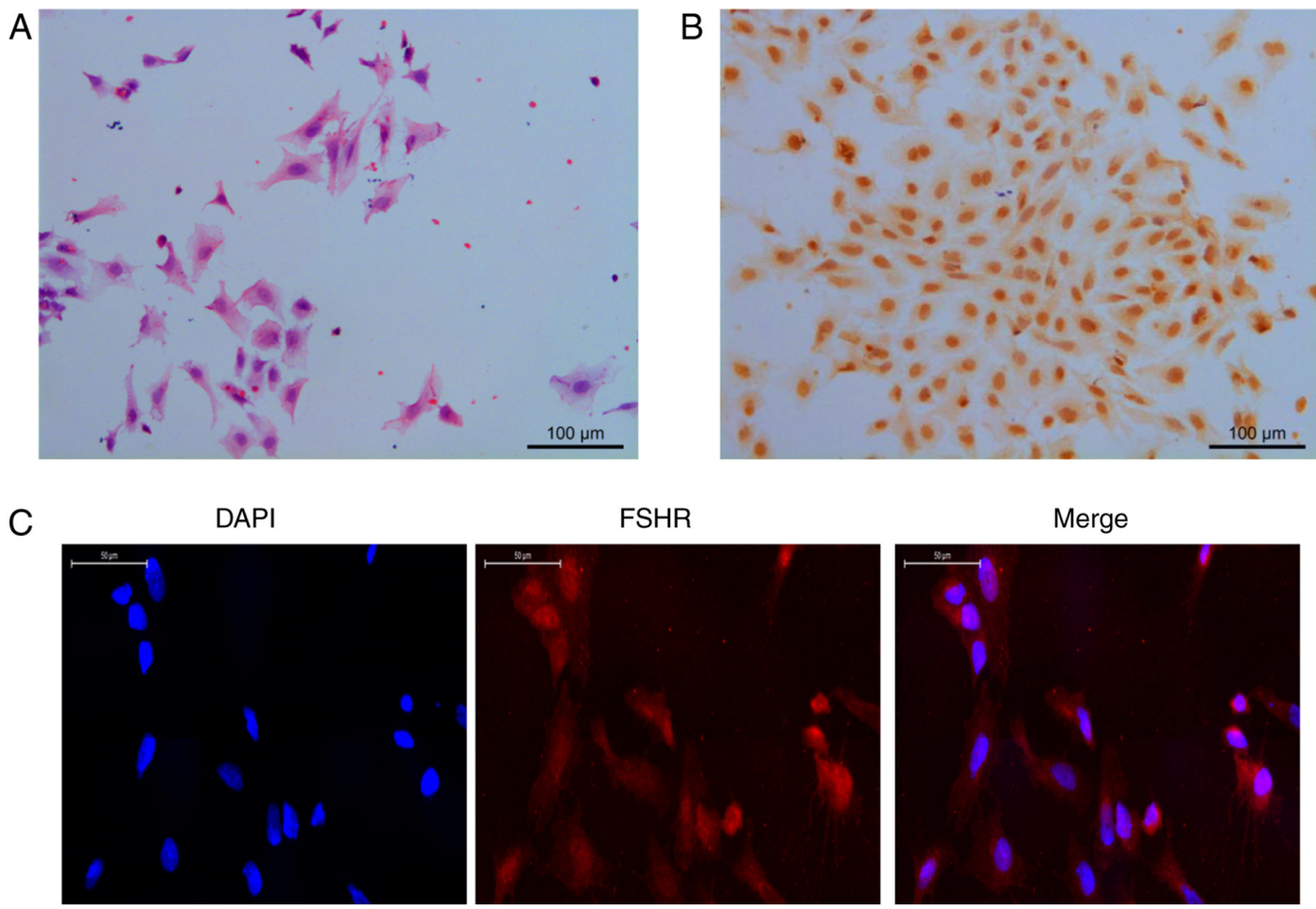

Figure 4. Morphology and identification of GCs (hematoxylin and eosin staining, magnification, x200; immunocytochemistry staining, magnification x200; IF staining, magnification x400). (A) GCs exhibited polygonal or cuboidal appearance under inverted phase contrast microscopy on adhering to the culture surface, proliferating, and spreading to form a monolayer. (B) FSHR-positive staining (yellow) was present in the nucleus and cytoplasm of GCs. IF staining was performed; (C) the positive rate was $>95 \%$, therefore, the GCs extracted met the requirements of subsequent trials. GCs, granulosa cells; FSHR, follicle stimulating hormone receptor; IF, immunofluorescence.

A

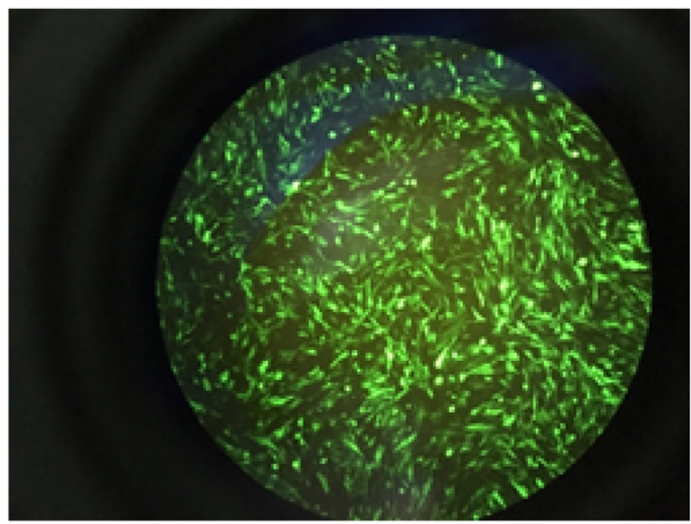

C

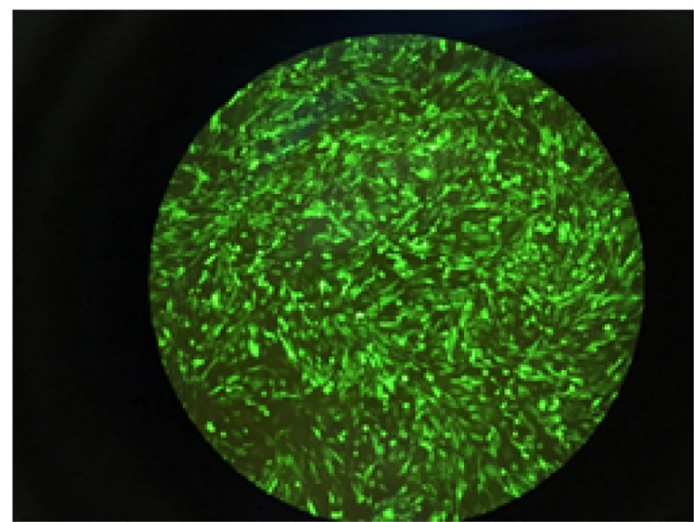

$\mathrm{B}$

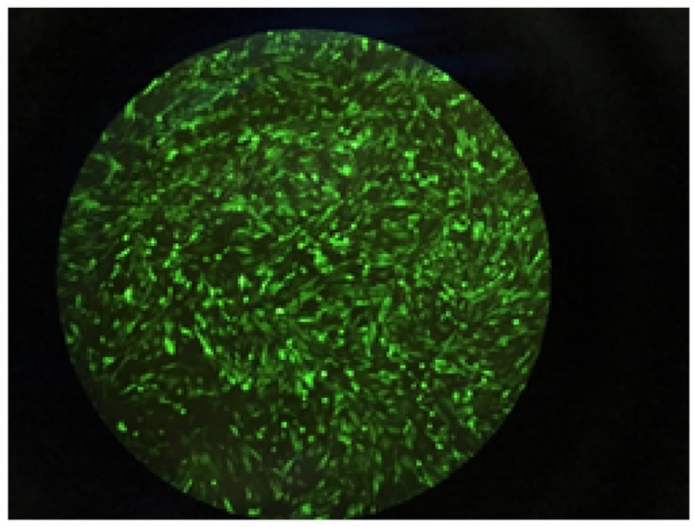

$\mathrm{D}$

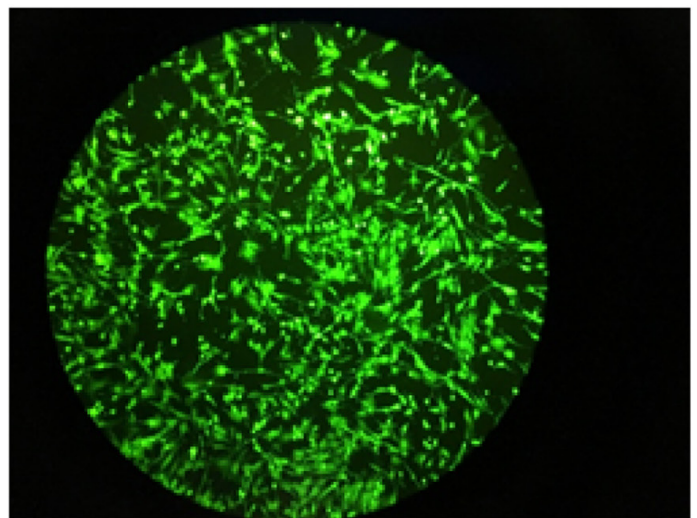

Figure 5. Expression of green fluorescence in GCs. (A) Oe negative control virus group, $10^{11} \mathrm{PFU} / \mathrm{ml}$, MOI=200; (B) FKBP4-Oe virus group, $2 \times 10^{10} \mathrm{PFU} / \mathrm{ml}$, MOI=400; (C) RNAi negative control virus group, $5 \times 10^{10} \mathrm{PFU} / \mathrm{ml}$, MOI=100; (D) FKBP4-RNAi virus group, 2x10 ${ }^{10} \mathrm{PFU} / \mathrm{ml}$, MOI=400). The cell transfection rate was $>80 \%$. Magnification, $x 100$. GCs, granulosa cells; MOI, multiplicity of infection. 

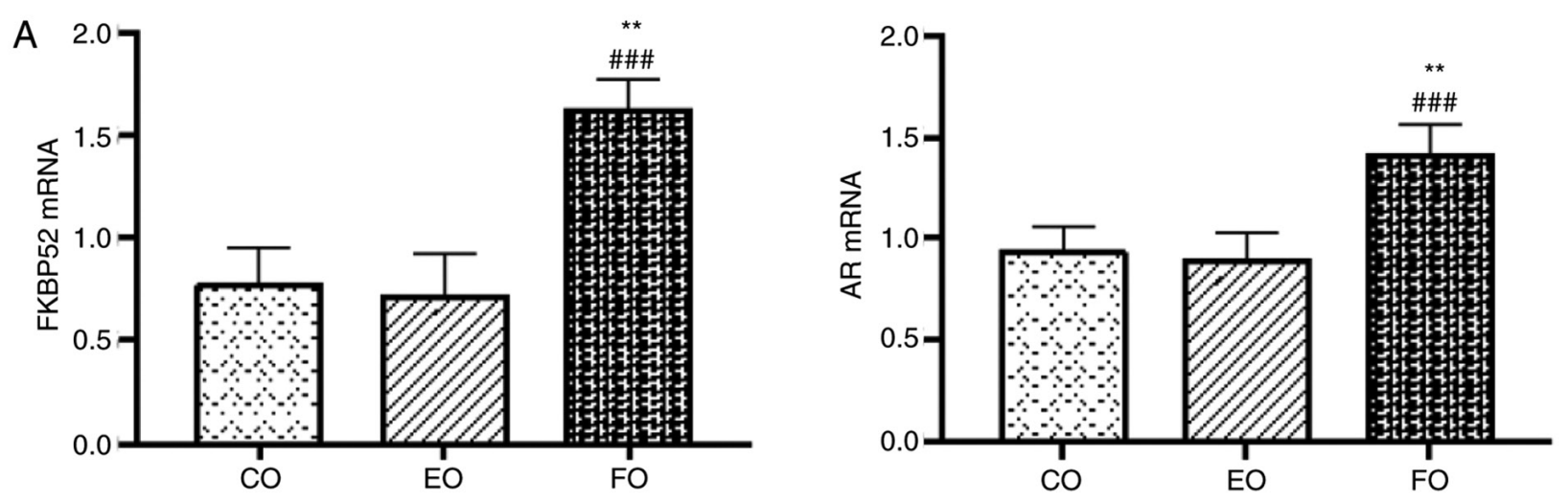

B $\quad$ AR $(99 \mathrm{kDa})$
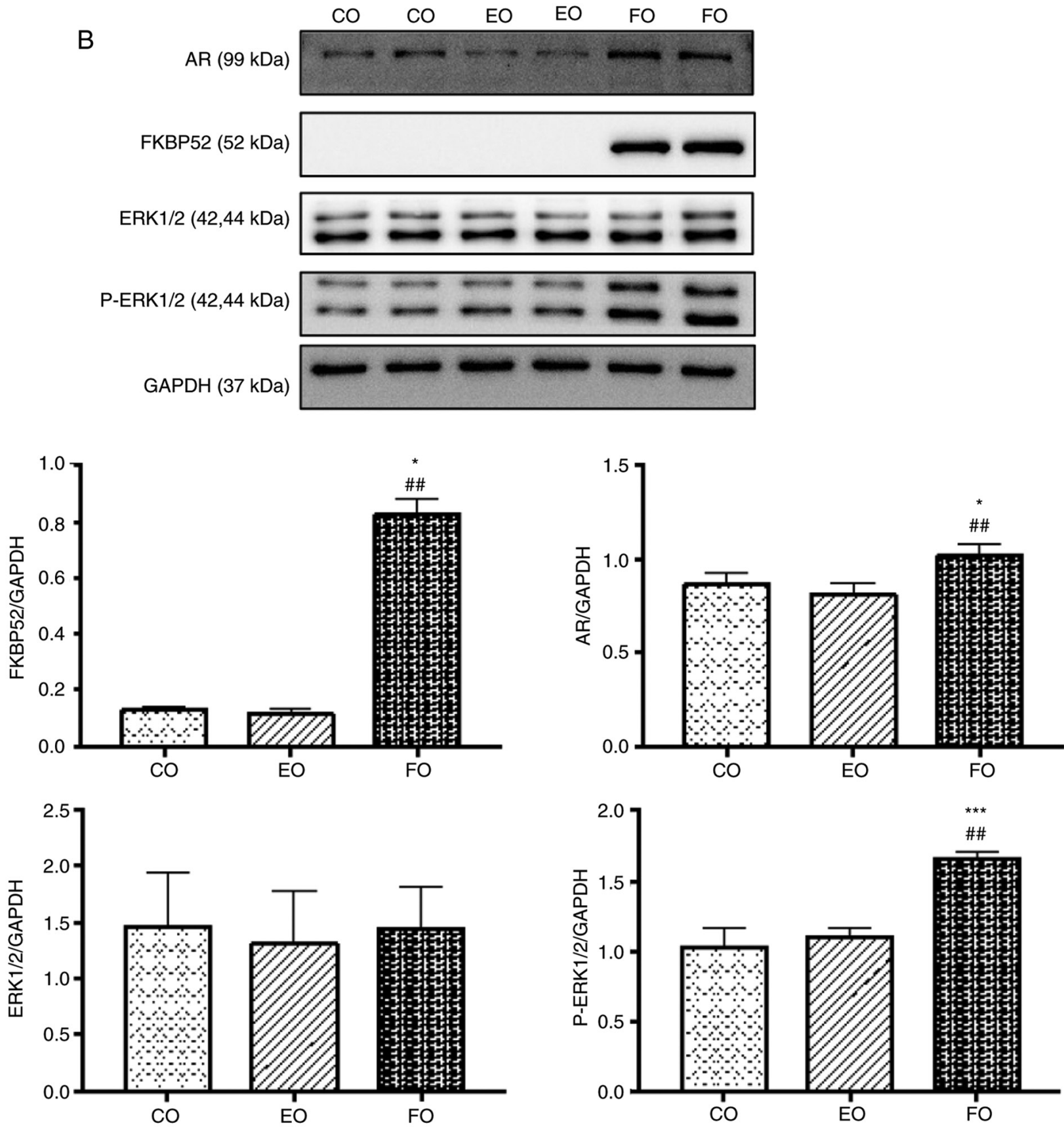

Figure 6. Expression of FKBP52, AR, ERK1/2 and p-ERK1/2 in GCs. (A) Comparison of the mRNA expression levels of FKBP52 and AR mRNA (mean $\pm \mathrm{SD}, \mathrm{n}=9$ per group). mRNA expression levels of FKBP52 and AR in the FO group were significantly higher than those in the CO and EO groups. No significant difference was found between the $\mathrm{CO}$ and EO groups $(\mathrm{P}>0.05)$. (B) Comparison of the protein expression levels of FKBP52, AR, ERK1/2 and $\mathrm{p}-\mathrm{ERK} 1 / 2$ (mean $\pm \mathrm{SD}, \mathrm{n}=6$ per group). Protein expression levels of FKBP52, AR and p-ERK1/2 in the FO group were significantly higher than those in the $\mathrm{CO}$ and EO groups. No significant difference was found between the $\mathrm{CO}$ and EO groups. Protein expression of ERK1/2 did not differ significantly among the groups. 

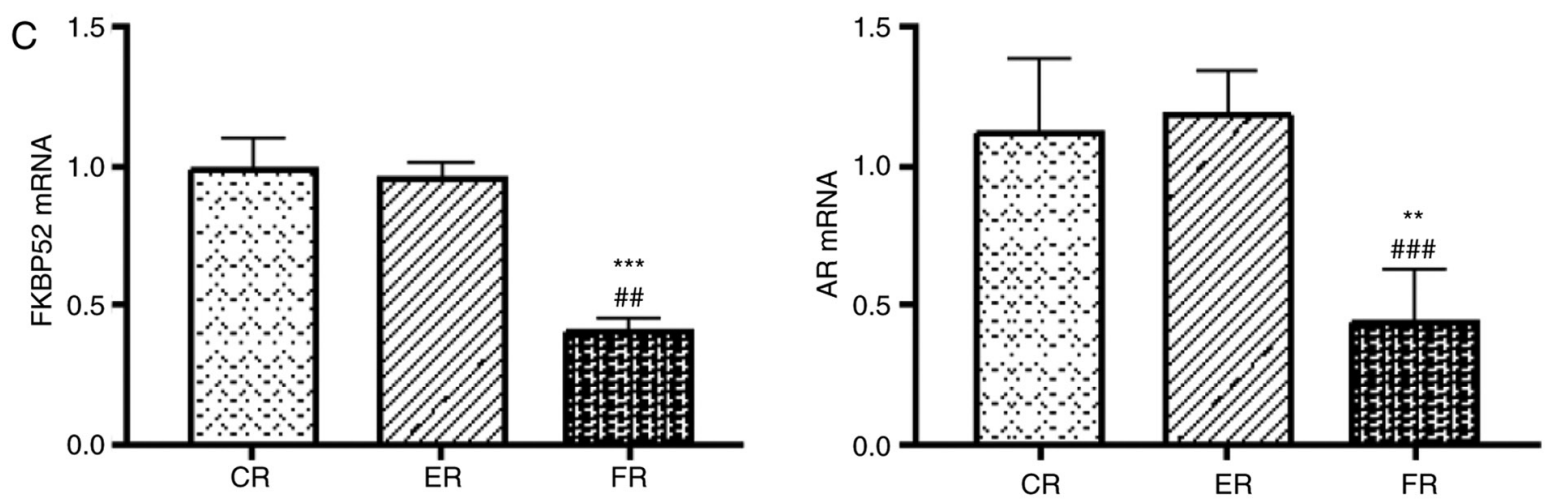

D $\quad$ AR $(99 \mathrm{kDa})$

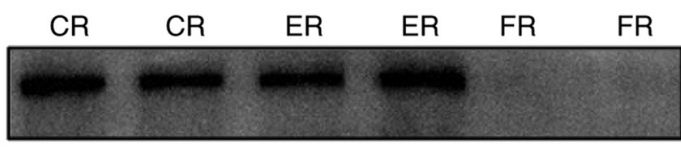

FKBP52 (52 kDa)

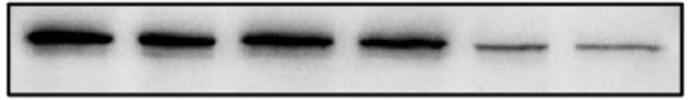

ERK1/2 (42,44 kDa)

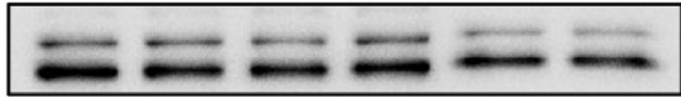

P-ERK1/2 (42,44 kDa)

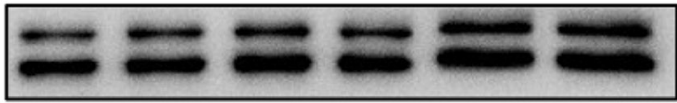

GAPDH (37 kDa)
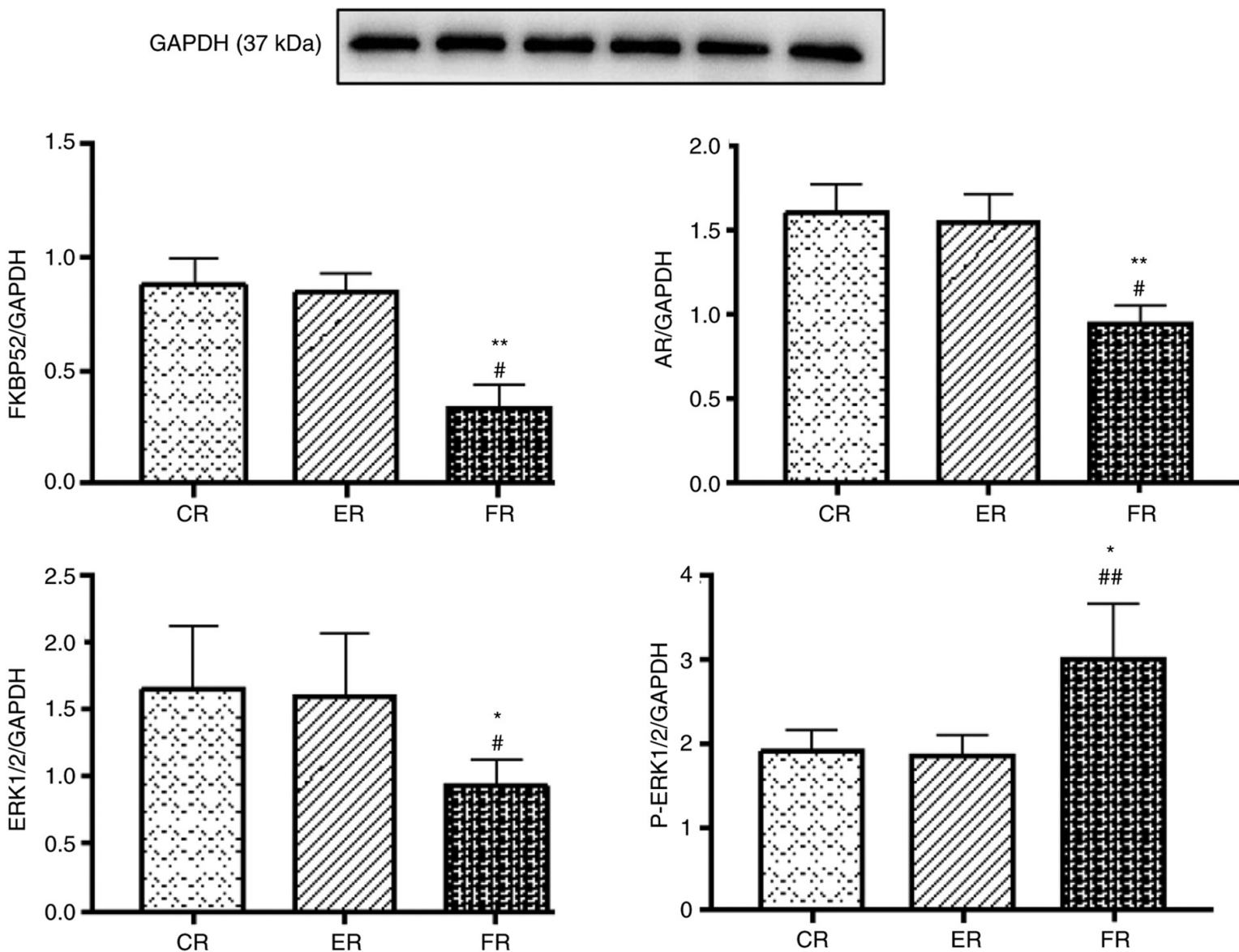

Figure 6. Continued. (C) Comparison of the mRNA expression levels of FKBP52 and AR (mean \pm SD, $n=9$ per group). mRNA expression levels of FKBP52 and AR in the FR group were significantly lower than those in the CR and ER groups. No significant difference was found between the CR and ER groups (P>0.05). (D) Comparison of the protein expression levels of FKBP52, AR, ERK1/2 and p-ERK1/2 (mean \pm SD, $n=6$ per group). Protein expression levels of FKBP52, AR and ERK1/2 in the FR group were significantly lower than those in the CR and ER groups. p-ERK1/2 showed the opposite result. No significant difference was found between the CR and ER groups. The experiment was repeated three times. ${ }^{*} \mathrm{P}<0.05, * * \mathrm{P}<0.01$ and $* * * \mathrm{P}<0.001 \mathrm{NC}$ group vs. $\mathrm{PM}$ group; \#P<0.05, $\# \# \mathrm{P}<0.01$ and \#\#\#P<0.001 OC group vs. PM group. FKBP52, FK-506 binding protein 52; AR, androgen receptor; ERK1/2, extracellular signal-regulated kinase; p-ERK1/2, phosphorylated ERK1/2; PM, polycystic ovarian syndrome model; NC, normal control; OC, oil control; SD, standard deviation. 


\section{Discussion}

PCOS is an endocrine disease featuring hyperandrogenism which has a multifactorial pathogenesis and heterogeneous clinical manifestations. Among all clinical manifestations, variant degrees of hyperandrogenism are present in the majority of patients with PCOS. The hyperandrogenism state of ovarian tissues in the PCOS population can lead to dysgenesis.

In the present study, PCOS rats had higher expression levels of FKBP52, AR and p-ERK1/2 in the ovary. Following adenovirus vector transfection of GCs, the protein expression levels of AR, ERK1/2 and p-ERK1/2 changed with FKBP4 gene silencing and overexpression.

PCOS model evaluation. At 35 days post-DHEA treatment, the vaginal smear (Fig. 1A), H\&E staining (Fig. 1C), and ELISA results (Fig. 1D) revealed that the PCOS model was successfully established. Differences between rats and humans in the mechanism of ovulation may explain why the ovarian weights and ovarian coefficients of the PM group rats were statistically lower in than the control groups (Fig. 1B).

FKBP52 in reproductive development. Previous studies on two independently derived FKBP52-deficient (52KO) mouse lines served a vital role in the reproductive development of mammals. Male 52KO mice exhibit phenotypes in accordance with partial androgen insensitivity, incorporating dysgenic prostate and seminal vesicles, ambiguous external genitalia covering hypospadias and retention of nipples into adulthood $(9,13)$. They had reduced epididymal sperm counts and motility (22), and the sperm showed abnormal morphology. Therefore, gene knock-out experiments in male mice have revealed FKBP52 as a crucial promoter of physiological AR activity $(9,13)$.

Female 52KO mice were yield as they exhibited normal morphology, ovulation and fertilization. The dysgenesis was the consequence of embryonic implantation and decidualization failure on account of progesterone insensitivity and uterine defects (23-25). In addition, FKBP52 may result in endometriotic lesions, with decreased expression levels of FKBP52 in patients with endometriosis, and increased cell proliferation, inflammation and angiogenesis resulting from progesterone resistance in $52 \mathrm{KO}$ mice (26). According to the above-mentioned findings, FKBP52 is important in reproductive development.

FKBP52, AR, and PCOS. Previous studies have provided evidence to support a direct pathological role for AR-mediated signaling in the development of PCOS $(27,28)$. It is an important extraovarian mediator (29). Certain findings have indicated how hyperandrogenism modulates AR ubiquitination, resulting in antral follicle growth arrest in a chronically androgenized PCOS rat model (30).

Few investigations have been performed on the impact of FKBP52 on PCOS. In a comparison of normal women of childbearing age with patients with PCOS using gene chip technology, FKBP52 protein-coding genes were different, and it may be closely associated with abnormal androgen PCOS and obesity phenotype (14). High-fat fed diabetic NONcNZO mice exhibited higher rates of peri- and post-implantation resorption, and had aberrant expression of uterine interferon- $\gamma$ and progesterone receptor (PGR) and its immunophilin co-chaperone FKBP52 at nidation (30). The aberrant PGR-targeted gene expression in PCOS-like rats pre- and post-implantation overlapped with dysregulated expression of FKBP52, which was linked to endometrial dysfunction and infertility (31).

The results in the present experiments revealed that the PM group had higher mRNA and protein levels of FKBP52 (Figs. 2 and 3) and AR (Fig. 3). This suggested that the overexpression of FKBP52 and AR in the ovaries of PCOS rats may be attributed to the stimulation of hyperandrogenism.

Morphology and identification of GCs. The H\&E staining showed that cells were polygonal or cuboidal under inverted phase contrast microscopy. As FSHR is a unique marker of GCs, its positive rate in IHC and IF staining was $>95 \%$. Therefore, the above results indicated that the GCs extracted met the requirements of subsequent trials (Fig. 4).

Adenovirus vector transfection of GCs. GCs have different MOIs when they meet different viral titers. An appropriate MOI not only guarantees the transfection rate, but also conserves virus usage. In the preliminary trial, when the cell transfection rate reached $\sim 80 \%$, the MOI was calculated using the formula described above. This met the requirements of subsequent trials (Fig. 5).

Activated AR in the cytoplasm may interact with several signaling molecules, which in turn converge on MAPK/ERK activation $(15,16)$. In the present study, the PM rats had higher expression levels of FKBP52, AR and p-ERK1/2 in the ovary. Therefore, it was hypothesized that FKBP52 mediates AR through the MAPK/ERK pathway. The Ad-siRNA-FKBP4-EGFP and Ad-Oe-FKBP4-EGFP adenovirus vectors were constructed to verify the association of FKBP52, AR and MAPK/ERK by transfecting GCs.

When FKBP4 was overexpressed, the mRNA and expression levels of FKBP52 and AR increased and that of p-ERK1/2 increased, whereas ERK1/2 showed no change (Fig. 6A and B). Following FKBP4 silencing, the mRNA and expression levels of FKBP52 and AR decreased, that of p-ERK1/2 increased and that of ERK1/2 decreased (Fig. 6C and D). This may be interpreted as the existence of a compensatory response and this requires verification in the future. To the best of our knowledge, this is the first time the above-mentioned results have been reported. To a certain extent, these results explain the association of FKBP52, AR and MAPK/ERK, and further verification is required to confirm this.

\section{Acknowledgements}

Not applicable.

\section{Funding}

The present study was approved the National Natural Science Foundation of China (grant no. 81674012).

\section{Availability of data and materials}

The datasets used and/or analyzed during the present study are available from the corresponding author on reasonable request. 


\section{Authors' contributions}

SS performed the experiments, participated in collecting data, performed the statistical analysis and drafted the manuscript. YT participated in study design and assisted in drafting the manuscript. Both authors read and approved the final manuscript.

\section{Ethics approval and consent to participate}

The present study was approved by the Experimental Animal Ethics committee of Nanjing University of Chinese Medicine (Nanjing, China).

\section{Patient consent for publication}

Not applicable.

\section{Competing interests}

The authors declare that they have no competing interests.

\section{References}

1. Chiofalo B, Laganà AS, Palmara V, Granese R, Corrado G, Mancini E, Vitale SG, Ban Frangež H, Vrtačnik-Bokal E and Triolo O: Fasting as possible complementary approach for polycystic ovary syndrome: Hope or hype? Med Hypotheses 105: 1-3, 2017.

2. Asemi Z, Samimi M, Taghizadeh M and Esmaillzadeh A: Effects of Ramadan fasting on glucose homeostasis, lipid profiles, inflammation and oxidative stress in women with polycystic ovary syndrome in Kashan, Iran. Arch Iran Med 18: 806-810, 2015 .

3. Franks S: Controversy in clinical endocrinology: Diagnosis of polycystic ovarian syndrome: In defense of the rotterdam criteria. J Clin Endocrinol Metab 91: 786-789, 2006.

4. Qu J, Wang Y, Wu X, Gao L, Hou L and Erkkola R: Insulin resistance directly contributes to androgenic potential within ovarian theca cells. Fertil Steril 91: 1990-1997, 2009.

5. Laganà AS and Pizzo A: Authors' reply to: 'Empiric' inositol supplementation in normal-weight non-insulin resistant women with polycystic ovarian disease: From the absence of benefit to the potential adverse effects. Arch Gynecol Obstet 291: 959-960, 2015.

6. Wang FF, Pan JX, Wu Y,Zhu YH,Hardiman PJ and Qu F: American, European, and Chinese practice guidelines or consensuses of polycystic ovary syndrome: A comparative analysis. J Zhejiang Univ Sci B 19: 354-363, 2018.

7. Tai PK, Maeda Y, Nakao K, Wakim NG, Duhring JL and Faber LE: A 59-kilodalton protein associated with progestin, estrogen, androgen, and glucocorticoid receptors. Biochemistry 25: 5269-5275, 1986

8. Davies TH and Sánchez ER: FKBP52. Int J Biochem Cell Biol 37: 42-47, 2005.

9. Cheung-Flynn J, Prapapanich V, Cox MB, Riggs DL, SuarezQuian C and Smith DF: Physiological role for the cochaperone FKBP52 in androgen receptor signaling. Mol Endocrinol 19: 1654-1666, 2005.

10. Periyasamy S, WarrierM,TillekeratneMP,Shou W and SanchezER: The immunophilin ligands cyclosporin A and FK506 suppress prostate cancer cell growth by androgen receptor-dependent and -independent mechanisms. Endocrinology 148: 4716-4726, 2007.

11. Lin JF, Xu J, Tian HY, Gao X, Chen QX, Gu Q, Xu GJ, Song JD and Zhao FK: Identification of candidate prostate cancer biomarkers in prostate needle biopsy specimens using proteomic analysis. Int J Cancer 121: 2596-2605, 2007.

12. De Leon JT, Iwai A, Feau C, Garcia Y, Balsiger HA, Storer CL, Suro RM, Garza KM, Lee S, Kim YS, et al: Targeting the regulation of androgen receptor signaling by the heat shock protein 90 cochaperone FKBP52 in prostate cancer cells. Proc Natl Acad Sci USA 108: 11878-11883, 2011.
13. Yong W, Yang Z, Periyasamy S, Chen H, Yucel S, Li W, Lin LY, Wolf IM,Cohn MJ,Baskin LS, et al: Essential role for Co-chaperone FKBP52 but not FKBP51 in androgen receptor-mediated signaling and physiology. J Biol Chem 282: 5026-5036, 2007.

14. Ketefian A, Jones MR, Krauss RM, Chen YD, Legro RS, Azziz R and Goodarzi MO: Association study of androgen signaling pathway genes in polycystic ovary syndrome. Fertil Steril 105: 467-473.e4, 2016.

15. McCubrey JA, Steelman LS, Chappell WH, Abrams SL, Wong EW, Chang F, Lehmann B, Terrian DM, Milella M, Tafuri A, et al: Roles of the Raf/MEK/ERK pathway in cell growth, malignant transformation and drug resistance. Biochim Biophys Acta 1773: 1263-1284, 2007.

16. Roberts PJ and Der CJ: Targeting the Raf-MEK-ERK mitogenactivated protein kinase cascade for the treatment of cancer. Oncogene 26: 3291-3310, 2007.

17. Peterziel H, Mink S, Schonert A, Becker M, Klocker H and Cato AC: Rapid signalling by androgen receptor in prostate cancer cells. Oncogene 18: 6322-6329, 1999.

18. Belani M, Deo A, Shah P, Banker M, Singal P and Gupta S: Differential insulin and steroidogenic signaling in insulin resistant and non-insulin resistant human luteinized granulosa cells-A study in PCOS patients. J Steroid Biochem Mol Biol 178: 283-292, 2018.

19. Miao ZL, Guo L, Wang YX, Cui R, Yang N, Huang MQ, Qin WB, Chen J, Li HM, Wang ZN and Wei XC: The intervention effect of Rosiglitozone in ovarian fibrosis of PCOS rats. Biomed Environ Sci 25: 46-52, 2012.

20. Anderson E, Lee GY and O'Brien K: Polycystic ovarian condition in the dehydroepiandrosterone-treated rat model: Hyperandrogenism and the resumption of meiosis are major initial events associated with cystogenesis of antral follicles. Anat Rec 249: 44-53, 1997.

21. Livak KJ and Schmittgen TD: Analysis of relative gene expression data using real-time quantitative PCR and the 2(-Delta Delta C(T)) method. Methods 25: 402-408, 2001.

22. Hong J, Kim ST, Tranguch S, Smith DF and Dey SK: Deficiency of co-chaperone immunophilin FKBP52 compromises sperm fertilizing capacity. Reproduction 133: 395-403, 2007.

23. Tranguch S, Cheung-Flynn J, Daikoku T, Prapapanich V, Cox MB, Xie H, Wang H, Das SK, Smith DF and Dey SK: Cochaperone immunophilin FKBP52 is critical to uterine receptivity for embryo implantation. Proc Natl Acad Sci USA 102: 14326-14331, 2005.

24. Tranguch S, Wang H, Daikoku T, Xie H, Smith DF and Dey SK: FKBP52 deficiency-conferred uterine progesterone resistance is genetic background and pregnancy stage specific. J Clin Invest 117: 1824-1834, 2007.

25. Yang Z, Wolf IM, Chen H, Periyasamy S, Chen Z, Yong W, Shi S, Zhao W, Xu J, Srivastava A, et al: FK506-binding protein 52 is essential to uterine reproductive physiology controlled by the progesterone receptor A isoform. Mol Endocrinol 20: 2682-2694, 2006.

26. Hirota Y, Tranguch S, Daikoku T, Hasegawa A, Osuga Y, Taketani Y and Dey SK: Deficiency of immunophilin FKBP52 promotes endometriosis. Am J Pathol 173: 1747-1757, 2008.

27. Caldwell AS, Eid S, Kay CR, Jimenez M, McMahon AC, Desai R, Allan CM, Smith JT, Handelsman DJ and Walters KA: Haplosufficient genomic androgen receptor signaling is adequate to protect female mice from induction of polycystic ovary syndrome features by prenatal hyperandrogenization. Endocrinology 156: 1441-1452, 2015.

28. Walters KA: Role of androgens in normal and pathological ovarian function. Reproduction 149: R193-R218, 2015.

29. Caldwell ASL, Edwards MC, Desai R, Jimenez M, Gilchrist RB, Handelsman DJ and Walters KA: Neuroendocrine androgen action is a key extraovarian mediator in the development of polycystic ovary syndrome. Proc Natl Acad Sci USA 114: E3334-E3343, 2017.

30. Lim JJ, Lima PDA, Salehi R, Lee DR and Tsang BK: Regulation of androgen receptor signaling by ubiquitination during folliculogenesis and its possible dysregulation in polycystic ovarian syndrome. Sci Rep 7: 10272, 2017.

31. Albaghdadi AJH and Kan FWK: Immunosuppression with tacrolimus improved implantation and rescued expression of uterine progesterone receptor and its co-regulators FKBP52 and PIASy at nidation in the obese and diabetic mice: Comparative studies with metformin. Mol Cell Endocrinol 460: 73-84, 2018.

This work is licensed under a Creative Commons Attribution-NonCommercial-NoDerivatives 4.0 International (CC BY-NC-ND 4.0) License. 